\title{
Sustainability of Heritage Neighborhoods in Kathmandu
}

\author{
Jibgar Joshi
}

\begin{abstract}
This paper critically examines the role of heritage in the development of Kathmandu in the past and raises the question of sustainability of its numerous neighborhoods in the wake of modern changes and increasing pressure on them. It depicts the ongoing conflicts between their conservation and modern ways of living. It explores the ways of linking urban management issues with the emerging concept of their sustainability. It draws some lessons from the experiences and pleads for integrating heritage resources for creating sustainable neighborhoods. It highlights the potentials of using the experience of Kathmandu in shaping new developments or in the renewal of traditional towns and shows how cities should be managed in the context of inclusiveness and sustainability.
\end{abstract}

Index Terms-Heritage, inclusive design, livability sustainable neighborhoods.

\section{INTRODUCTION}

A distinctive feature of ancient towns in Nepal is their social cohesiveness. In the past, there was no polarization; the rich and the poor were integrated within the social system Their inclusiveness was due to the fact that they were intertwined with the prevailing ways of life. The purpose of this paper is to explore how the experience of such towns can be used to further develop the concept of sustainable neighborhood.

People organize themselves to create a community; a neighborhood. They share their joys and woes in it. They fulfill their needs through it. They participate in the community activities. [1] They serve their community according to their interest and ability.

A city is composed of many neighborhoods. We will have a sustainable city out of several inclusive communities. All, irrespective of their age, sex, and creed, will work to create a better environment to work and live in. In a sustainable neighborhood, all the sections of the population will be engaged in activities they like. It is based on the principle of co-existence. It reduces conflicts and crime; and thus increases security. It allows for an extensive use of social networks. It increases self-reliance. It will make the urban economy resilient, as the outside influence is likely to be resisted. It helps to revert to activities that are more sustainable. It is responsive to the needs of the future generation.

The concept is also related with inclusiveness that will enable all to get integrated with the urban economy as a whole. [2] There should be opportunities for everyone to participate fully with access to a variety of quality jobs.

Manuscript received July 12, 2014; revised November 14, 2014.

Jibgar Joshi is with School of Environmental Science and Management (SchEMS), P.O. Box 2453, Kathmandu, Nepal (e-mail: jibgarj@ gmail.com)
It should be able to manage disparity and provide opportunities for a varied group of individuals. Failure to manage for disparity will limit the ability of the people to make choices about how and where they live. This will lead to polarization and conflicts impairing the social connections that are vital for living a vibrant and thriving life.

Communities must be able to influence and manage the space and activities themselves. People should be engaged in finding out the real causes of a problem and potential solutions. This will create a feeling of ownership to the process of transformation among the users.

\section{ElEMENTS OF Sustainable NeIGHBORHOOD}

The concept of sustainable neighborhood should aim to energize and regenerate a community through the creation of pleasing environments that add value to cities. It should provide residents with opportunities and choices to thrive and reach their full potential.

Hanson views inclusive environment as "one in which all users, whatever their abilities, are able to carry out their day to day activities comfortably, effectively and safely without being restricted by the poor design, maintenance or management of the built environment." [3]Designs should create inclusive spaces, which contribute to the fulfillment of the needs of all types of people, and make places and programs accessible to all. Humans have a diverse range of needs and abilities. These can be shaped and changed greatly through the promotion of inclusive design manifesting itself as a sustainable neighborhood in physical terms. Successful design enables people across the entire social range to participate in and receive value from actions. It helps to create space that provides a sense of place that people identify with where they want to live and work.

Actions emerge from the needs, assets and culture of the communities and the environment in which they exist. Their success should be seen in terms of their contribution in meeting the needs of the users, such as health, education, and safety. There must be good transportation and communication. Access to goods and services should be ensured in order to make these available to all the inhabitants regardless of age, sex, religion, or income, or power. Sustainable actions will provide the people with tools they need to manage or control their environment. For making such designs, it is necessary to formulate and implement strategies to avoid:

- Neighborhoods with diverse qualities of life;

- Conflicts between the physical environment and vision in terms of cultural values;

- Unequal access to education, health and jobs;

- Urban slums; 
- Environmental shortcomings such as lack of parks and open spaces, ugly landscapes, and polluted rivers;

- Loss of community identity and a sense of belonging; and

- Loss of civic values and responsibility.

The vitality of a place depends on the transformation of the culture, which is possible if their character and identity are not lost. Livability depends on the ability to create an environment that depicts harmony between culture, built environment and nature. Every culture wants to retain its identity. If we fail to understand this, heritage sites will turn into problem areas with lost character. [4] With the increase in the population and changes in values and aspirations, ecosystems change. There has always been resistance to changes. Sustainability of new changes depends on their compatibility with the existing culture. It is necessary to assess the implications of changes. For instance, due to the growth of population and activities as well as the changes in the modes of transport, the public spaces and road junctions designed to fulfill the needs of the medieval ages will definitely not serve the present day needs.

The works done through external help may not add value to the local community to a significant level. It is not only fair but also more cost-effective to engage the local community in the management of the environment and in dealing with the impacts of their activities. The increasing cost of infrastructure and services under public undertakings also proves this point.

\section{HERITAgE RESOURCES AND EXPERIENCE}

Kathmandu Valley has a picturesque setting of terraced field and surrounding hills with Himalayan peaks. Scenic landscapes, terraced fields, wildlife, birds, butterflies, and the natural flora are the natural assets that form the basis for natural heritage in the Valley.

Kathmandu was founded about one thousand years ago as the city of Kasthamandap. Along with the city, many other small neighborhoods developed during the Lichhavi period are still intact. The historic settlements have been built and rebuilt several times in the past. They have direct association with gods and temples. Their physical structures were dedicated to gods. Thimi is famous for pottery; and Khokana for mustard oil. The Valley is a depository of artistic treasures in the form of magnificent stupas, pagodas, temples, images and carvings with archaeological, historic and religious values. The surrounding terraced hills with marvelous settings and a panorama of the Himalayan ranges are yet another source of scenic beauty. The monuments are a part of the people's daily life. Life is based on religious beliefs and sincerity to their tradition. There are a vast number of shrines, temples, palaces, palace squares, ageless sculptures and legends. These are intertwined with its cultural traits. Culture is a major asset for Kathmandu Valley. [5]This is true in both crowded historic towns and isolated villages with people living in close harmony with nature. The Valley has numerous sites of great archaeological, historic and religious values. The major monuments are:

- Pagodas, temples, shrines and stupas;
- Ancient palaces, courtyards and statues;

- Historic towns with residential buildings, squares, lanes, stone water taps, backyards, bahals and bahis; and

- Arts and paintings.

Its cultural charm is found in the form of diverse festivals around the year. The indigenous people have perpetuated the culture and helped the integration of their culture with the changing development trend. People's daily life and the works of farmers, artisans, carpenters, painters and sculptors do represent living culture. The culture is reinforced by structure and settings; ethnic diversity and costumes; religion and festivals; dances and music; and legends and myths.

From birth to death, special rite and rituals and celebrations mark the important events of one's existence that entails a symbiosis of body and soul with the divine. Festivals are expressions of life reflecting its joys and sorrows, and fears and dreams. They are interrelated and observed round the year. They are mysterious, colorful and full of fun. They have their roots and motives in the religion. They may reflect legendary belief and superstition and follow the seasons of crop harvesting. Some of the festivals are unique to Kathmandu and some are observed by specific communities or neighborhoods. Because of the agrarian economy, rich culture and favorable climatic conditions, outdoor activities are always preferred.

However, the charm of outdoor activities is declining due to increasing traffic, noise, pollution and encroachment with incompatible activities. This also made public spaces less accessible with the rapid disappearance of shared private spaces. There is a decline in the use of public spaces for religious, cultural and social functions, while commercial encroachment has increased. [5] Community life has become weakened due to lack of integration of changes with the original aim of the neighborhoods.

Looking from the ecological perspective their sustainability can be understood against a variety of internal and external forces. [4] It is the local people along with their aspirations and energies, which can extend the life of their ecosystem with culture. [4] Nepal's experience in the conservation and upgrading of historical towns like Bhaktapur shows that it is necessary to:

- Integrate culture and development through planning. Instead of controlling new developments, these should be made compatible with heritage sites for cultural transformation. In the process, the character and identity associated with the heritage should be retained.

- Provide technological options to the people to make full use of the heritage sites [6].

- Understand social changes before making physical changes. It is much more difficult to live in the cultural history than to appreciate the value and beauty of it. [6] With the modernization, people will be forced to make changes in their social life that may not be compatible with the cultural needs.

- Discourage modern development trends. Most of these might not be for the benefit of the people. In order to ascertain which modern changes are compatible or which elements can be well integrated, research on sustainable development becomes necessary. There is a 
lack of conservation techniques and knowledge. Cultural degeneration has taken place not because of ignorance, illiteracy and even poverty, but because of affluence and increase in economic opportunities due to commercialization. The lesson that can be learnt is that cities should not raise their standards just like that [7].

- Develop a culture of working with the people. It is not possible to work against the people [6].

- Encourage training and HRD activities and build capacity for inclusive designs.

\section{EMERGING PROBLEMS AND ISSUES}

Kathmandu Valley is becoming less inclusive over time due to the failure to transform in line with the modern trends. There is an erosion of cultural and religious values.

Shift to unsustainable ways of living such as high-rise apartment building at places where there is acute shortage of services and chaotic transport system has threatened the urban life in many ways. The exposure of ancient towns to outside economies has not only made them less inclusive but also weakened their economy. It is true that core areas are not adequate to cater to the modern needs (e.g., room space, parking area, sunlight, fresh air etc.). However, the increasing cost of modern amenities can be borne only through higher city income and productivity, which is not happening.

Many neighborhoods in city core areas are losing population. The native Newars are migrating away to housing colonies located in the fringe areas. Migrants' settlements are growing in parallel [5].

Cities face increasing and a diverse set of problems relating to different groups such as the youth, senior citizens, and differently abled persons and so on. Their needs and problems are naturally different. As inclusiveness depends on the ability to avoid the exclusion of any group, awareness on population programs will help to enhance it. It is necessary to satisfy the needs of different age-groups of the population. The perspectives of different groups of people are different. "For what most people see and often want in cities is not what planners, decision makers and elite groups see and want. It varies for children, for workers, for immigrants for people of different ages, incomes, occupations, and cultural backgrounds." [8] Being not inclusive is the root cause of the problem; we have conflicts, crimes, sexual abuses, girl trafficking etc. as its symptoms.

Poverty has made neighborhoods more cohesive with interdependency among its members. The need to depend on the community decreases as the family income increases but this is not the solution as the family during the transition sacrifices most of the things it had been enjoying. It is not necessarily good for a society in transition to move to modern ways that are more conventional. Moreover, the failure to retain social networks with mutual help leads to the loss of inclusiveness in society.

Some of the problems of urban designs in responding to the sustainability issues are change in the values, threats of modern ways, increasing discrimination, limited awareness etc. The recent drive for better transport without due consideration to the change in transport demand due to landuse changes has also disrupted the environment in inner neighborhoods.

In terms of sustainability, community formation is the most difficult task; and as such is ignored in new developments. It is used only for sharing of utility costs or for shifting the responsibility from the management team to users' group. The cost of community formation is formidable, whether in modern housing or in land pooling project areas.

\section{TOWARDS SUSTAINABLE NEIGHBORHOODS}

The concept of sustainable development has deep implications on our way of doing things, our behaviors, and values. It is necessary to evolve a process where all will be integrated. We need to ensure that the results of our development are distributed in a fair way. It is necessary to manage different aspects of urban development in order to ensure sustainability and enhance inclusiveness. Table I below shows some of the key aspects of urban management in the context of inclusiveness and sustainability. The concept of inclusiveness and sustainability has implications on how we manage our cities.

The following measures will help to make cities more inclusive:

- Encourage local activities;

- Increase awareness on community life;

- Provide key services locally;

- Engage the inhabitants in upgrading environment and social works;

- Invest in cultural and religious features;

- Promote walking for sustainable mobility;

- Form cooperatives in the neighborhood; and

- Ensure sustainable financing of infrastructure.

Inclusive designs should promote the access for all to space for diverse uses such as eating places and groceries at convenience, open space and parks, places for meditation, sports and recreation, etc. [9] The city should be composed of safe neighborhoods with a range of dwellings to accommodate diverse needs. Housing and building codes should focus more on health, safety and community quality of life.

There should be full access to quality education with choices. It should be realized that the physical condition of a school does have an impact on a child's ability to learn.

In order to enhance access and mobility, viable public transit system should be developed. Cities can create incentives and promote policies that favor mass transit. Safe, functional and green connections to neighborhoods will help to restore the public realm and make them more inclusive. Pedestrian streets will reactivate the public realm. These along with mixed land uses will help to reintegrate. Coexistence of varied activities and cultural behaviors will help enhance cosmic characteristics; a key element of cosmopolitan transformation in cities. [10] It increases harmony and peace and perpetuates spiritual dimension of life [11].

Heritage sites and well-maintained and usable open space are virtually the only urban places where people of 
different income level have equal access. Parks and open space are instrumental for improved air and water quality, for preserving rivers, and for city greening. They provide community facilities and gathering spaces. Spaces and places are required to create and display social and cultural rituals that have meaning for all residents. Public events, such as street fairs and dramas, make neighborhood life vibrant. It is necessary to encourage the community-based initiatives and integrate these with the city level structures and networks. It should be functional; loved by its residents. It should adapt to the changes that are taking place.

TABLE I: SOME ASPECTS OF URBAN MANAGEMENT IN THE CONTEXT OF INCLUSIVENESS AND SUSTAINABILITY

\begin{tabular}{|c|c|c|}
\hline $\begin{array}{l}\text { Urban } \\
\text { management }\end{array}$ & Inclusiveness & Sustainability \\
\hline $\begin{array}{l}\text { Public spaces } \\
\text { and cultural } \\
\text { assets }\end{array}$ & $\begin{array}{l}\text { Universal access } \\
\text { meeting the cultural, } \\
\text { social and physical } \\
\text { needs of all }\end{array}$ & $\begin{array}{l}\text { Productive utilization } \\
\text { and sustainable use } \\
\text { with cost recovery }\end{array}$ \\
\hline Mobility & $\begin{array}{l}\text { Availability of } \\
\text { convenient and } \\
\text { affordable public } \\
\text { transport at close } \\
\text { proximity }\end{array}$ & $\begin{array}{l}\text { Promotion of } \\
\text { non-motorized } \\
\text { transport within the } \\
\text { neighborhood }\end{array}$ \\
\hline $\begin{array}{l}\text { Provision of } \\
\text { urban } \\
\text { services }\end{array}$ & $\begin{array}{l}\text { Universal access } \\
\text { meeting the needs of } \\
\text { all }\end{array}$ & $\begin{array}{l}\text { Community } \\
\text { involvement with sense } \\
\text { of belonging }\end{array}$ \\
\hline $\begin{array}{l}\text { Urban } \\
\text { environment }\end{array}$ & $\begin{array}{l}\text { Sense of collective } \\
\text { belonging for } \\
\text { enhancing the social } \\
\text { good }\end{array}$ & $\begin{array}{l}\text { Sustainable use of } \\
\text { resources and } \\
\text { consumption practices }\end{array}$ \\
\hline $\begin{array}{l}\text { Economy and } \\
\text { economic } \\
\text { base }\end{array}$ & $\begin{array}{l}\text { Self-reliance for } \\
\text { resilient local } \\
\text { economy }\end{array}$ & $\begin{array}{l}\text { Sustainable linkages } \\
\text { with outside } \\
\text { economies }\end{array}$ \\
\hline $\begin{array}{l}\text { Community } \\
\text { mobilization }\end{array}$ & $\begin{array}{l}\text { Civic engagement } \\
\text { with participation and } \\
\text { partnership in the } \\
\text { provision of services }\end{array}$ & $\begin{array}{l}\text { Integration of } \\
\text { communities for } \\
\text { cosmopolitan } \\
\text { development }\end{array}$ \\
\hline Governance & $\begin{array}{l}\text { Social cohesiveness } \\
\text { and democracy with } \\
\text { equitable access for all } \\
\text { to resources and } \\
\text { decision making } \\
\text { processes }\end{array}$ & $\begin{array}{l}\text { Intergenerational } \\
\text { equity with respect to } \\
\text { sustainable use of } \\
\text { natural and cultural } \\
\text { resources }\end{array}$ \\
\hline
\end{tabular}

The potentials of a sustainable neighborhood should be used in making development more sustainable. This can be done through the following measures:

- Emerging urban areas should be planned and developed as eco-towns where relatively rural characteristics and lower standards could prevail.

- Upgrading of old towns and settlements with a view to make them more inclusive is a sustainable strategy that needs to be pursued. [12] The potentials of social network and the heritage can be used with the revival of indigenous activities.

Resources are not only used fully, but additional resources bound with the people are also made available. People being tied with their community are motivated to be happier as they have a purpose to make their place a better one. Most of the services that are provided locally are likely to satisfy them more because they can be tailored to their needs.

Sustainable neighborhood is created out of a functioning and thriving community. An ideal society is the one where human needs are satisfied through the community efforts, and where they are inspired to add value to the community they belong to and they identify themselves with. Here the people live in harmony with their environment; and are less vulnerable to different types of risks. As they do not have to worry much to satisfy their own needs, they are enabled to contribute as much as they can. Their happiness depends on the services they are able to provide to their community. They find convenient environment to work. For emulating such a society, it is necessary to think of manageable communities. Sustainable neighborhood should be designed to foster such communities in the form of eco-towns, eco villages or healthy cities. A sustainable neighborhood is a place where such a society thrives. It is inclusive also in the sense that whatever you contribute will add value to the social good.

For an inclusive design, we should therefore consider the way families in a community interact with each other. It should influence the process of their overall development and their engagement in different activities. It should allow mixed uses while promoting the coexistence of various uses based on their compatibilities.

Although the historic towns of Kathmandu Valley are good examples of sustainable neighborhoods, there is an increasing threat. One can easily observe conflicts of interest between the global trend and the inherent primitive characteristics. Time and again, there had been attempts to impair their inherent characteristics for more than a century. Some of the factors that sustain their inclusiveness may be summarized as follows:

- Primitiveness with strong resistance to change;

- Cohesive and all-inclusive design;

- Encouragements for pedestrians;

- Culture of sharing poverty; and

- Sharing of urban space with opportunities for mixing together due to cultural and religious activities throughout the year.

Heritage based neighborhoods in the past in Kathmandu Valley used to be sustainable and inclusive and provided good livable ambience. Some examples of sustainable practices are "Saa ga" method of solid waste management; festival of "sithi nakha" for cleaning and maintaining of water sources; and "dhunge dhara" as a traditional source of water supply. Although they are surviving, this paper views that there is a decline in the quality of life due to several reasons such as failure to integrate the increasing transport need with the sanctity of the heritage sites, failure to sustain their economic utility as per the changing economic needs and social transformation etc. Their potentials are not considered in new developments. Sustainability is undermined while exploiting heritage resources whether for tourism, transit or revenue generation. There is a tendency to make money through their undue exposure and exploitation without any regard for the need to conserve. Heritage is a 
good source of municipal revenue but very little is invested in conservation for sustaining the revenue.

Earlier, roads used to be a part of built environment. People gathered and celebrated cultural and social functions on roads. Now roads have divided communities. The new approach is also to create vibrant environment at places accessible to transits. Neighborhoods are encroached and disrupted through transits. Transit is seldom integrated with their development. There is an inadequate emphasis on the use of public spaces including road junctions and privately shared spaces for creating vibrant urban ambience. The territory of many important temples has been compromised for immediate traffic relief. Their sustainability can be enhanced if they were accessed through non-motorized means into mass transit points. Even in the case of housing colonies, potential buyers prefer housing projects where they expect to find residents of similar ethnic background. Community formation is easier with homogeneous groups in terms of their economic behaviours. Trust should be built-in through working together attitude to solve the community problems. There is a strong link between governance and sustainable provision of urban services. [13].

\section{CONCLUSION}

Heritage neighborhoods can help cities become more sustainable. They should be conserved as integral parts of urban transformation. The past experiences including their adjustments and resistance to change are useful in creating sustainable neighborhoods in the context of changing needs and emerging challenges. Different aspects of urban development should be interlinked with their inclusiveness and sustainability. It is necessary to relate their potentials in the provision of services and goods as well as governance, Due to primitiveness and the persistent resistance to change, large scale investments with ability to destroy the inherent character of the settlements never thrived. However this had immense costs and the life of the common person had not been an easy one. The role of the government must change and help the community actions to transpire their inclusiveness. It should understand that modern changes will be resisted in absence of adaptation measures; and any sort of conflict of interest will make development more costly and unsustainable. It is necessary to work with the people in implementing policies that will make living easier and more pleasing to make neighborhoods more inclusive as well as sustainable. Heritage neighborhoods should be sustained through their integration with the transformation to modern living unlocking their potentials towards sustainability.

\section{REFERENCES}

[1] J. Egan. The Egan Review: Sustainable Communities. [Online]. Available: www.eauc.org.uk/sorted/files/egan_review.pdf.

[2] Asian Development Bank, Inclusive Cities, Mandaluyong City: ADB, 2011.

[3] J. Hanson. The Sustainable Neighbourhood: Delivering a more Accessible Urban Environment Through Inclusive Design. [Online]. Available: http: www.eprints.ucl.ac.uk/3351.

[4] J. Joshi, Managing Environment and Cities for Sustainable Development, Kathmandu: Lajmina Joshi, 2011.

[5] K. K. Joshi, "Making space for modern needs: kathmandu's historic past and its gamble with urbanization," Journal of Applied Physics, vol. 3 no. 2, October 2009.

[6] A. Haaland, Bhaktapur: A Town Changing, rev. ed. Kathmandu: GTZ, 1985.

[7] J. Joshi, Planning for Sustainable Development: Urban Management in Nepal and South Asia, Kathmandu: Lajmina Joshi, 2000.

[8] L. Rodwin, Cities and City Planning, New York, London: Plenum Press, 1981 , pp. $8-18$.

[9] D. Iacofano and S. Goltsman. Inclusive Design: Moving Beyond New Urbanism. [Online]. Available: http://www.inclusivecity.com.

[10] M. Safier, The Cosmopolitan Challenge in Cities on the Edge of the Millennium: Moving from Conflict to Co-Existence, 1996, pp. 12 - 29.

[11] A. Wakhlu, "Back to the roots: spiritual insights into sustainable urban development," presented at the $13^{\text {th }}$, ADIPA Biennial Conference, Bangkok, 1999.

[12] J. Joshi, Housing and Urban Development in Nepal, Kathmandu: Lajmina Joshi, 3d. ed. 2013.

[13] J. Joshi "Sustainable provision of urban environmental services in kathmandu valley," presented at the $2^{\text {nd }}$ ICBED, University Sains Malaysia, Dec. 2-4, 2008.

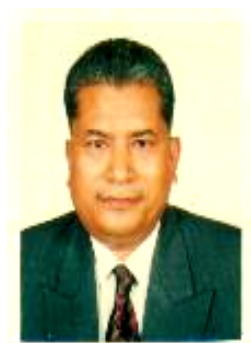

Jibgar Joshi was born in Kathmandu on December 1,1948 . He is an urban and regional planner. He got the degree of bachelor of civil engineering with honors in 1971 from Jadavpur University, Calcutta. He later studied economics and law and received the degree of B. L. in 1975 and M.A. in 1974 from Tribhuvan University, Kathmandu. He obtained his $\mathrm{PhD}$ in 1981 from Tribhuwan University; the title of his dissertation being regional planning with special reference to Nepal. $\mathrm{He}$ was a humphrey/SPURS fellow at the Department of Urban Studies and Planning, MIT during the year 1987/88. He received P. G. diploma in housing, planning and building from IHS, Rotterdam in 1983.

He offers courses to M.Sc. students at Urban Planning Program, Institute of Engineering and SchEMS. He also supervises thesis works of master's students. He is a freelance consultant and has just completed his assignment with an ADB TA project as an urban development and landuse specialist. His current research interests include urbanization and inclusive development.

Dr. Joshi is a life member and the former president of Regional and Urban Planners' Society of Nepal. He is a life member of Nepal Engineers Association. He is also a life member and former president of Nepal Association of Humphrey Fellows. He is the author of more than eight books and many research papers. His books include: Housing and Urban Development in Nepal, 2013, Managing Environment and Cities for Sustainable Development 2011, Regional Strategy for Development: A case study of Nepal, 1985. 